\title{
Influence of infection by Sacculina carcini (Cirripedia, Rhizocephala) on consumption rate and prey size selection in the shore crab Carcinus maenas
}

\author{
Martin H. Larsen ${ }^{\text {a }}$, Jens T. Høeg ${ }^{\text {b }}$, Kim N. Mouritsen ${ }^{\text {a,* }}$ \\ a Department of Bioscience, Marine Ecology, University of Aarhus, Ole Worms Allé 1, DK-8000 Aarhus C, Denmark \\ ${ }^{\mathrm{b}}$ Department of Biology, Marine Biology Section, University of Copenhagen, Universitetsparken 4, DK-2100 Copenhagen, Denmark
}

\section{A R T I C L E I N F O}

\section{Article history:}

Received 26 March 2013

Received in revised form 30 May 2013

Accepted 31 May 2013

Available online $\mathrm{xxxx}$

\section{Keywords:}

Community structure

Feeding behavior

Feminization

Host-parasite interaction

Mytilus edulis

Parasitism

\begin{abstract}
A B S T R A C T
Parasites generally influence the feeding behavior of their host and may therefore indirectly impact ecosystem structure and functioning if the host plays an ecological key role. The ecologically important shore crab (Carcinus maenas) is commonly infected by the rhizocephalan parasite Sacculina carcini that aside from inflicting behavioral change, castration and ceased molting, also feminizes its male host morphologically. The latter results in reduced cheliped size, and, together with the other parasite-induced effects, this may potentially impact host feeding behavior. In two separate laboratory experiments, we offered infected and uninfected adult male crabs respectively ad libitum small, easy-to-handle blue mussels (Mytilus edulis) (10-15 $\mathrm{mm}$ in shell-length), and a limited, size-structured prey population (15-45 mm in shell-length; seven size-classes, ten mussels per class) during 10-15 days. Corrected for carapace width, the per capita consumption rate of the infected and uninfected crabs was similar in either experiment, both regarding number of mussels and amount of tissue dry-weight consumed. Also, the median mussel size preyed upon when exposed to the size-structure prey population was unaffected by infection. However, infected crabs preyed less frequently $(26 \%)$ on intermediate mussel sizes $(25-30 \mathrm{~mm})$ than uninfected crabs. For both infected and uninfected crabs the median prey size increased linearly with maximum claw height. Host dry weight was significantly reduced by infection, assumed to be the result of the morphological feminization (reduced appendage size) rather than reflecting poorer general condition of infected individuals. Infected crabs were nonetheless subjected to a higher mortality rate than uninfected crabs during the experimental period. We conclude that Sacculina infection has a very limited effect on its host crabs' feeding biology and that any measurable ecosystem ramifications of the host-parasite association must originate from other processes; for instance reduced mean size (infection inhibits molting) and density (infection increases mortality) of the crab population where parasitism is high.
\end{abstract}

(c) 2013 Elsevier B.V. All rights reserved.

\section{Introduction}

Parasites are ubiquitous components of marine environments with the potential to affect the behavior, energetic requirement, condition, reproduction and survival of their hosts (Lafferty and Kuris, 2009; Moore, 2002; Mouritsen and Poulin, 2002; Sousa, 1991). If the host is a keystone species or otherwise ecologically dominant, such host-parasite interactions may ultimately influence the organization and functioning of coastal communities (Mouritsen and Haun, 2008; Mouritsen and Poulin, 2002, 2010; Wood et al., 2007).

The shore crab, Carcinus maenas (Linné, 1758), is a widely distributed and often abundant epibenthic predator that inhabits intertidal soft and hard bottom habitats of European coasts and estuaries. It was inadvertently introduced to the Atlantic coast of North America

\footnotetext{
* Corresponding author. Tel.: + 4587156113.

E-mail address: kim.mouritsen@biology.au.dk (K.N. Mouritsen).
}

in the early 19th century and has since then colonized some regions of Japan, Australia, Argentina, South Africa, Tasmania and western North America (see Darling et al., 2008). Throughout its distributional range, the shore crab is an ecologically influential species in benthic communities, particularly as a consequence of its feeding ecology (Grosholz and Ruiz, 1995; Grosholz et al., 2000; Reise, 1985). The diet of the shore crab consists of a variety of invertebrate species as well as teleosts and macroalgae, but it often exhibits a preference for bivalves, particularly thin-shelled species such as the blue mussel (Mytilus edulis) (Baeta et al., 2006; Lee and Seed, 1992; Mascaró and Seed, 2001; Raffaelli et al., 1989; Reid et al., 1997). Because the crab also prefers certain bivalve size classes, it may impact not only the abundance but also the size distribution of bivalves (Burch and Seed, 2000; Elner and Hughes, 1978; Mascaró and Seed, 2001).

The shore crab serves as host for the rhizocephalan barnacle Sacculina carcini Thompson, 1836. Cyprids of S. carcini settle on the crab cuticle, penetrate into the hemocoel and develop an internal 
root-like network (interna) throughout the tissue of the crab. On maturation, a part of the interna ruptures the crab's abdominal exoskeleton and forms a saclike structure (externa) containing the reproductive organs of the parasite (Høeg and Lützen, 1995). The infection prevalence of $S$. carcini in the shore crab population show great spatio-temporal variation usually ranging between a few to $20 \%$, and can locally even reach 40-90\% (Lützen, 1984; Mathieson et al., 1998; Rasmussen, 1973; Torchin et al., 2001; Werner, 2001; Zetlmeisl et al., 2011; unpublished data).

S. carcini infects and castrates both sexes of $C$. maenas and inhibits molting (Høeg, 1995), reduces general condition (Mouritsen and Jensen, 2006) and increases the mortality rate of infected crabs (Goddard et al., 2005). In addition, male shore crabs generally become behaviorally and morphologically feminized, the latter involving also a reduction in cheliped size (Høeg, 1995; Kristensen et al., 2012; Lafferty and Kuris, 2009; Mouritsen and Jensen, 2006).

Given the ecological important role of shore crabs in benthic communities it is crucial to understand whether and to what extent parasitism alter the feeding biology of the crab, of which nothing is presently known. This is further underlined by the fact that S. carcini has never been introduced together with its hosts during shore crab invasions outside Europe (Thresher et al., 2000).

Parasitism generally affects the feeding behavior of hosts (Moore, 2002) and because infection by S. carcini results in reduced size in the claws of male crabs, a decisive part of the feeding apparatus, this parasite can potentially have a profound impact on its host's foraging behavior. Hence, the aim of the present investigation was to evaluate the impact of $S$. carcini infections on the consumption rate and prey size selection by male shore crabs, C. maenas, using blue mussels, M. edulis, as prey.

\section{Materials and methods}

During August-October 2011, two indoor mesocosm experiments were performed at Rønbjerg Marine Biological Station, Limfjorden, Denmark ( $\left.56^{\circ} 53^{\prime} 27^{\prime \prime} \mathrm{N}, 9^{\circ} 9^{\prime} 57^{\prime \prime} \mathrm{E}\right)$. The first experiment, carried out between 28th August and 7th September (10 days), examined the consumption rate of uninfected and Sacculina infected male shore crabs C. maenas on blue mussels M. edulis. The second experiment, carried out between 4th and 19th October ( 15 days), was designed to determine the preferred mussel size classes eaten by uninfected and Sacculina infected male crabs, respectively. Solely male hosts were used in the experiments because only this gender becomes morphologically feminized by the infection. Female $C$. maenas do not develop super-feminization as a result of $S$. carcini infection (e.g., Kristensen et al., 2012).

\subsection{Collection and storage of experimental animals}

In S. carcini the time of development from larval infection to adult parasite lasts about a year, and it was therefore impractical to produce infested crabs experimentally (Høeg, 1995; Werner, 2001). Specimens of $C$. maenas were collected during June-September 2011 at several locations in the Limfjord using pots and eel traps. These were baited with frozen or fresh fish and typically deployed for $24 \mathrm{~h}$ at depths ranging from 1 to $7 \mathrm{~m}$. In the laboratory, uninfected and Sacculina infected crabs were sorted out and stored separately until commencement of the experiments. Infection status was determined by the presence or absence of an S. carcini externa located on the ventral surface of the crab's abdomen. The externa contains the female reproductive system and two cryptic dwarf males (Høeg, 1995). The shore crabs were stored in containers submerged in large basins with continuously running seawater at ambient temperature and fed crushed blue mussels ad libitum. Crabs were held under these conditions for at least one week prior to experimentation. Only undamaged male crabs were used in the experiments (no missing limbs and no visual damage to the body cuticle). Only crabs hosting sexually mature $S$. carcini externae were selected for the experimental units with infected crabs (see below). The mature externa of $S$. carcini appears as a sac-like structure, pale yellow to orange/light brown in color and typically measuring between 13 and $18 \mathrm{~mm}$ in maximum width (Lützen, 1984) (Fig. 1).

Blue mussels, M. edulis, were sampled August-September 2011 from a long-line aquaculture situated in the Limfjord. This ensured homogenous shell characteristics and flesh content among the applied mussels. The mussels were maintained in large tanks with well-aerated running seawater at the same water temperature and light regime as the crabs. The mussels were stored in the tanks for a maximum of 3 weeks prior to the experiments.

\subsection{Consumption rate}

A 15 L rectangular plastic container $(34 \times 26 \times 17 \mathrm{~cm}$; length $\times$ width $\times$ height) served as the experimental unit in which shore crabs and blue mussels were established. Each unit was covered with a lid to prevent crabs from escaping during the experiment and supplied with $2 \mathrm{~cm}$ beach sand, rinsed and sieved through a $1 \mathrm{~mm}$ screen, and its own seawater supply (27-30\%) at a flow rate of $0.3 \mathrm{~L} \mathrm{~min}^{-1}$. Three centimeters below the top of the container, a small hole $\left(0.3 \mathrm{~cm}^{2}\right)$ served as water outflow. The outflow was placed at the opposite end of the influx of water to allow water flow through the container, thus yielding an effective exchange of water during the experiment. The setup had a water depth of $12 \mathrm{~cm}$ and a water retention time of ca. $35 \mathrm{~min}$. The water temperature was measured every $30 \mathrm{~min}$ by submerged temperature loggers and the resulting mean temperature during the experiment was $17.0^{\circ} \mathrm{C}$ (range: $16.1-18.2{ }^{\circ} \mathrm{C}$ ).

Sixty experimental containers were arranged in five rows of twelve units. Thirty shore crabs of each infection status (i.e. Sacculina infected and uninfected) were individually added haphazardly to the containers, so that six infected and six uninfected crabs were placed in each of the five rows. The uninfected and infected crabs were matched according to carapace width $( \pm 1 \mathrm{~mm})$, measured as the distance between the tips of the anterior carapace spines. The overall mean carapace width was $57.6 \pm 0.4$ (SE) $\mathrm{mm}$ (size range: 51.7-64.8 mm), and mean width did not differ between treatments (infected/non-infected crabs; Student's $t$-test, $t_{58}=0.023, p=$ 0.982 ). Crabs were starved for $24 \mathrm{~h}$ in the experimental containers prior to the addition of blue mussels to standardize hunger levels. In

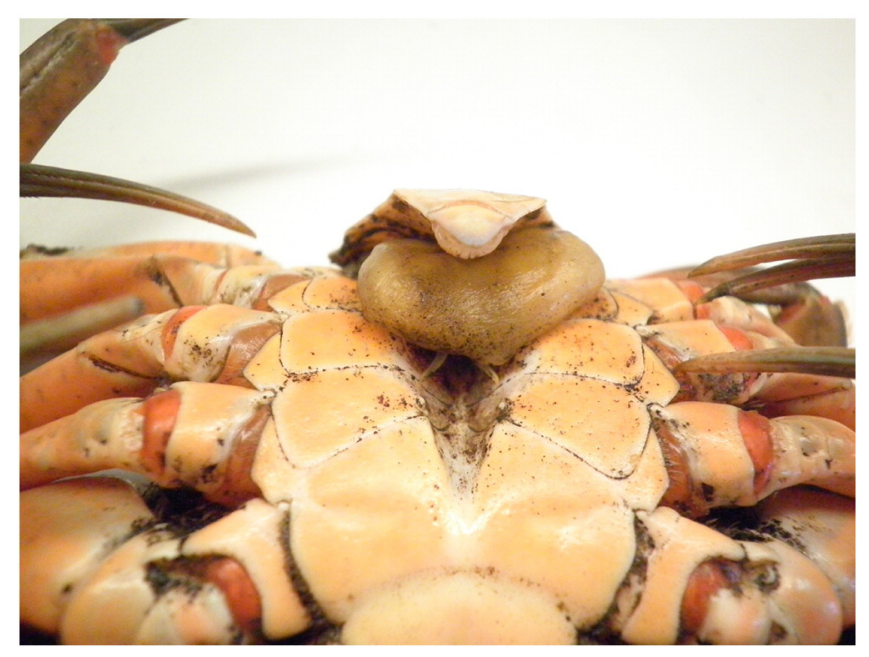

Fig. 1. Ventral view of a shore crab (Carcinus maenas) infected by the rhizocephalan Sacculina carcini, showing an adult externa (containing the parasite ovary) below the abdomen of the host. Photo: Sissel N. S. Geyti. 
addition, crabs were allowed to acclimatize to the applied experimental conditions during this period.

Initially, 40 blue mussels ranging in shell length (maximum anterior-posterior dimension) from 15 to $20 \mathrm{~mm}$ were added to each container within a PVC-ring $(1.5 \mathrm{~cm}$ in height and an inner diameter of $10 \mathrm{~cm})$ glued onto a tile $(14.5 \times 14.5 \times 0.5 \mathrm{~cm}$; length $\times$ width $\times$ height) placed in the center of the container. The PVC-ring was aligned to the sediment surface and only the inner part of the PVC-ring was not covered with substrata. This allowed the blue mussels to anchor to the tile by their byssus threads, ensuring that al mussels were fully accessible to the crabs by vision and touch during experimentation. Throughout the experimental period, additional blue mussels were added daily to the containers. The number of mussels in each container was never below five individuals, thus allowing ad libitum feeding. The blue mussels used in the experiment had a mean shell length of $18.0 \pm 0.14$ (SE) mm. Their average shell-free tissue dry weight was $21.4 \pm 0.7(\mathrm{SE}) \mathrm{mg}(\mathrm{n}=100)$, determined after drying at $110{ }^{\circ} \mathrm{C}$ for $24 \mathrm{~h}$. Pilot studies ascertained that all sizes of Sacculina infected and uninfected crabs used in the experiment were equally able to handle and consume mussels between 15 and $20 \mathrm{~mm}$ in shell length (see also Fig. 4).

After ten days, the crabs were removed and the number of uneaten blue mussels in each container was recorded to determine the crabs' consumption rate. To ensure that all mussels were recovered from the experimental units, the sediment was sieved through a $1 \mathrm{~mm}$ screen. The number of uneaten mussels within the PVC-ring was also counted after two days to examine potential difference in the temporal pattern of prey consumption between the infected and uninfected crabs during the experiment. Mussels were not counted at a daily basis to avoid disturbing and stressing the crabs any further. As a proxy for claw closing force, the propal height (maximum claw height) of the crabs' crusher (usually right) and cutter (usually left) claw was measured to the nearest $0.1 \mathrm{~mm}$. The maximum width of the crabs' third and sixth abdominal segment was also measured to the nearest $0.1 \mathrm{~mm}$. This was done to compare the relative abdominal width (RAW), defined as the ratio between the third and sixth abdominal width, between the uninfected and infected crabs. Male shore crabs infected by $S$. carcini tend to be morphologically feminized, including a relatively broader abdomen (Kristensen et al., 2012). Hence, RAW serves as a proxy for the degree of parasiteinduced morphological feminization (smaller RAW values indicate broader abdomen). After measurements, the crabs were killed by freezing, cleaned for macroscopic epibionts such as barnacles and subsequently desiccated at $110{ }^{\circ} \mathrm{C}$ in a drying cabinet until a constant weight was obtained to determine the dry weight. It was not possible to remove the internal root system of $S$. carcini from parasitized crabs. Since the Sacculina externa also constitutes an integral part of the parasite body, this was accordingly not removed before drying. Hence, the dry weight of infected crabs includes both host and parasite tissues.

\subsection{Prey size selection}

This experiment followed the experimental design and protocol as above with the following exceptions. The mean water temperature during the experiment was $13.5^{\circ} \mathrm{C}$ (range: $11.5-15.4{ }^{\circ} \mathrm{C}$ ) and the sediment depth in the containers was $1.5 \mathrm{~cm}$. The latter allowed the blue mussels to attach to the bottom of the experimental units by their byssus threads and still be readily accessible by vision and touch at the surface of the substrate. The crabs ranged in carapace width from 37.2 to $57.5 \mathrm{~mm}$ with an overall mean of $46.7 \pm 0.9$ (SE) $\mathrm{mm}$.

To determine the prey size selection of the infected and uninfected crabs, respectively, each crab was presented once to 70 blue mussels, comprising ten individuals in each of seven size classes: 15, 20, 25, 30, 35,40 and $45 \pm 1 \mathrm{~mm}$. The blue mussels were scattered haphazardly over the sediment bottom in each of the 60 experimental units. At experimental termination, the number of mussels eaten from each size class was recorded. Blue mussels that died (open shells) but remained uneaten during the experiment were not included in the predation estimate, and these mussels were not replaced with new individuals. The non-predatory mortality rate of blue mussels was low (0.8\%) and occurred mainly among mussels from 35 to $45 \mathrm{~mm}$. An additional random sample of ten mussels from each of the seven size classes was used for obtaining shell-free tissue dry weight after drying at $110{ }^{\circ} \mathrm{C}$ for $24 \mathrm{~h}$. These data were used to produce a regression between mussel dry weight and shell length and, in turn, calculate the total dry weight consumption for each crab individual during the experiment.

\subsection{Data analyses}

The consumption rate of blue mussels by uninfected and Sacculina infected crabs was evaluated using a paired $t$-test (paired according to carapace width $\pm 1 \mathrm{~mm}$ ). Relationships between consumption and crab dimensions were evaluated by linear regression on untransformed data. Survival rates were analyzed by chi-square tests.

As an estimate of median size of blue mussel eaten by uninfected and Sacculina infected crabs, we calculated the shell length at which $50 \%$ of the mussels were consumed in each experimental unit, referred to as median lethal (or prey) size $\left(\mathrm{LS}_{50}\right)$, from approximated sigmoidal curves using SigmaPlot 11.0 software. To correct for carapace width, the $\mathrm{LS}_{50}$ value for the uninfected and infected crabs was subsequently evaluated by a paired $t$-test. As a supplement, the numbers of mussels consumed by the uninfected and infected crabs in each of the seven mussel size classes were also compared by paired t-tests. Relationships between $\mathrm{LS}_{50}$, carapace width and claw height were evaluated by linear regression and the influence of claw height and infection status on the $\mathrm{LS}_{50}$ value was assessed by ANCOVA. All $\mathrm{LS}_{50}$ analyses were performed on untransformed data.

Experiments on prey choice (here size classes) are associated with problems of independence, which makes the use of most complex statistical analyses invalid (see e.g. Bruzzone and Corley, 2011; Roa, 1992). In order to circumvent this, we designed the experiment for simple paired analyses and contrasted solely infected and uninfected crabs, either for each prey size class separately, or for a single central tendency $\left(\mathrm{LS}_{50}\right)$.

The relationship between carapace width and dry weight of the uninfected and infected shore crabs were in both experiments analyzed by ANCOVA on log-transformed data. In addition, the propal height of the right and the left claw as well as the RAW was compared among the uninfected and infected crabs by paired $t$-tests.

Prior to the main parametric tests, we tested for the assumptions of homogeneity of variance and normal distribution. The statistical analyses were performed in SPSS 20.0 (Statistical Package for the Social Sciences). Variation in association with recorded mean values is given as standard error $( \pm S E)$ throughout.

\section{Results}

\subsection{Consumption rate}

Two Sacculina infected shore crabs died during the experiment and these individuals were excluded in further analyses. Statistically, S. carcini did not impact the survival rate of the infected shore crabs negatively in this experiment (proportion of infected versus uninfected surviving: $\left.\chi^{2}{ }_{1}=2.069, p=0.150\right)$.

Including all experimental units, a total of 7879 blue mussels, M. edulis, were consumed during the experiment. The mussel consumption did not differ significantly between the uninfected and infected crabs on either day two or day ten (paired $t$-test correcting for carapace width, $t_{27} \leq 0.262, p \geq 0.796$ ). In fact, the per capita 
daily mean consumption rate of the uninfected and infected crabs was identical at experimental termination (day 10): 13.6 mussels for both groups (Fig. 2), corresponding to $280.2 \mathrm{mg}$ mussel dry weight per day. Moreover, the consumption rate was for both infected and uninfected crabs unrelated to carapace width (albeit close to positive for uninfected; linear regression, $\mathrm{df}=26-28: r^{2} \leq 0.115, p \geq 0.067$ ), dry weight $\left(r^{2} \leq 0.037, p \geq 0.327\right)$ and propal height of largest claw $\left(r^{2} \leq 0.015, p \geq 0.541\right)$. Hence, the dimensions of the experimental crabs explain only a small and insignificant part of the variance in consumption rate, when crabs were presented solely to small prey items.

The dry weight and the carapace width of shore crabs were positively correlated both among uninfected $\left(r_{28}^{2}=0.796, p<0.0005\right)$ and Sacculina infected $\left(r_{26}^{2}=0.823, p<0.0005\right)$ individuals (Fig. $\left.3 A\right)$. An analysis of covariance on crab dry weight including carapace width as covariate, status of infection as fixed factor and their interaction, showed a significant effect of carapace width $\left(F_{1}, 54=228.98\right.$, $p<0.0005)$. Excluding the non-significant interaction between status of infection and carapace width $\left(F_{1,54}=0.241, p=0.626\right)$ the subsequent reduced model also demonstrated a significant effect of infection status on the crabs' dry weight $\left(F_{1,55}=20.73, p<0.0005\right)$. The dry weight of the infected crabs was on average $3.4 \%$ lower than that of uninfected crabs. Because the parasite tissue was not removed from the infected crabs prior to the analysis, the observed difference in dry weight between the infected and uninfected individuals is conservative: the difference would be larger had the parasite tissue been removed before drying.

Corrected for carapace width, the propal height of the right (paired $t$-test, $t_{27}=3.632, p<0.0005$ ) and the left (paired $t$-test, $t_{27}=6.124, p<0.0005$ ) claw differed significantly between the uninfected and infected crabs. The mean height of the right and the left claw of infected crabs was respectively 8.7 and $14.1 \%$ lower than that of uninfected crabs. In addition, the RAW of infected crabs was $10.1 \%$ lower than that of uninfected, indicating parasite-induced feminization (broader tail) of the former (paired $t$-test, $t_{27}=7.696$, $p<0.0005)$.

\subsection{Prey size selection}

One uninfected crab molted and seven infected crabs died during experimentation. Moreover, one Sacculina infected and one uninfected crab appeared physically weakened at the end of the experiment. These animals were excluded in further analyses. In contrast to the consumption rate experiment, $S$. carcini negatively influenced the survival rate of infected crabs in this experiment $\left(\chi^{2}{ }_{1}=7.705, p=\right.$ 0.006).

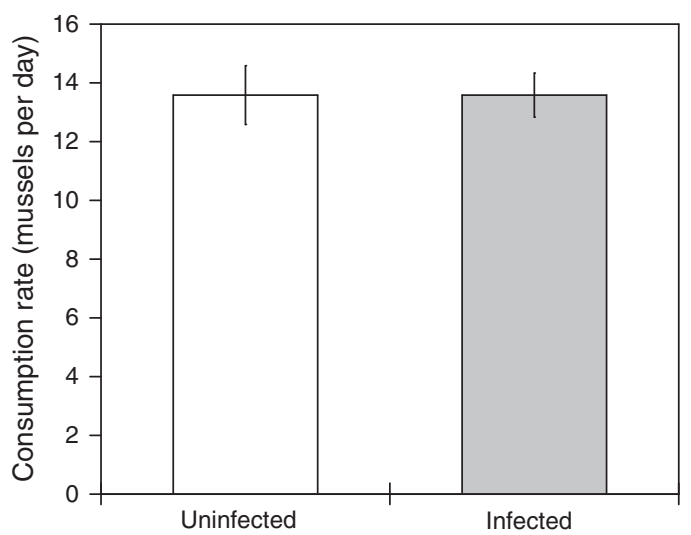

Fig. 2. Daily consumption rate (mean $\pm \mathrm{SE}$ ) of blue mussels, Mytilus edulis, between 15 and $20 \mathrm{~mm}$ in shell length by uninfected $(\mathrm{n}=30)$ and Sacculina infected $(\mathrm{n}=28)$ shore crabs (Carcinus maenas) during a 10-day laboratory experiment.

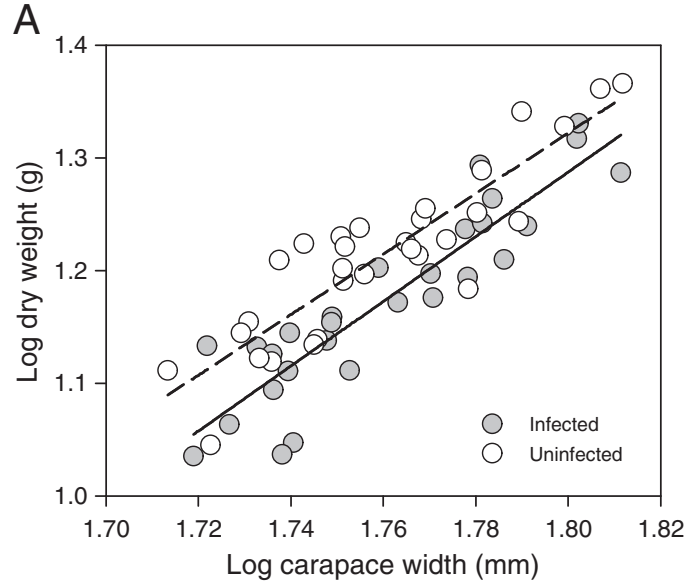

B

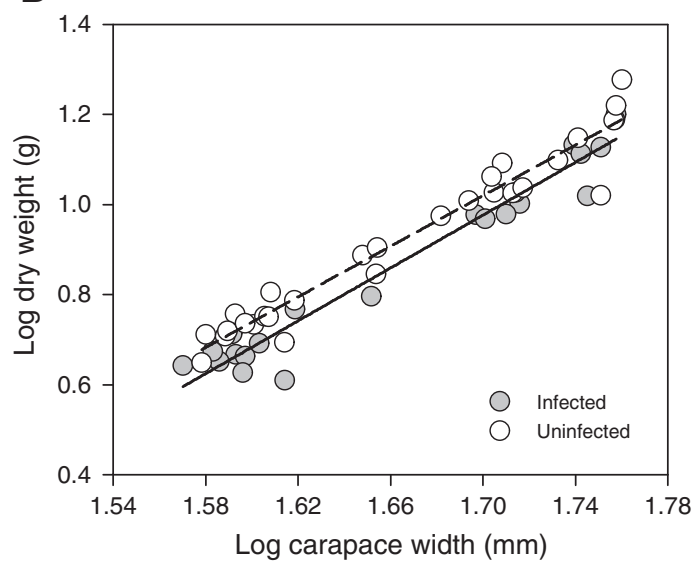

Fig. 3. The log-transformed relationship between dry weight and carapace width for uninfected (open circles, broken line) and Sacculina infected (closed circles, unbroken line) shore crabs (Carcinus maenas) in (A) the consumption rate experiment (uninfected crabs: $\mathrm{n}=30$, infected crabs: $\mathrm{n}=28$ ) and (B) in the size preference experiment (uninfected crabs: $n=28$, infected crabs: $n=22$ ). Note the different scales in the two plots.

Irrespective of infection status, the crabs preferably consumed mussels between 15 and $25 \mathrm{~mm}$ (82.3\% of all mussels consumed) and only few $40-45 \mathrm{~mm}$ mussels (2.1\%) were eaten (Fig. 4). This indicates that blue mussels larger than $40 \mathrm{~mm}$ are not readily accessible to shore crabs with a carapace width less than $57.5 \mathrm{~mm}$. Based on

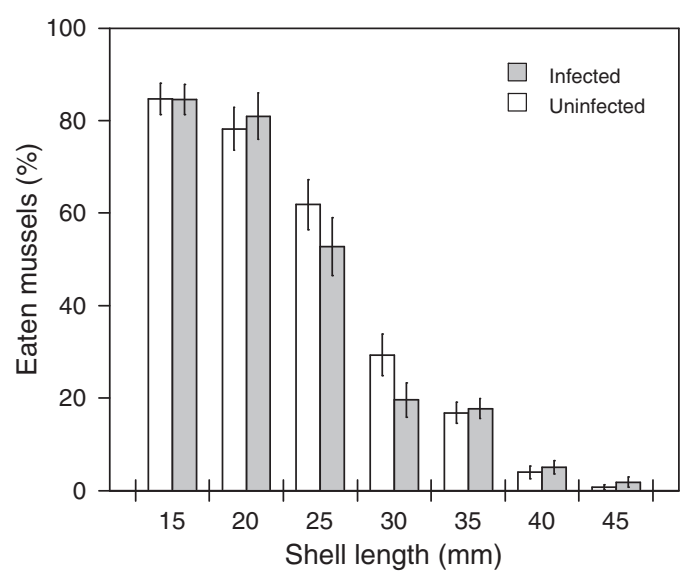

Fig. 4. Mean number $(\%, \pm \mathrm{SE})$ of consumed blue mussels, Mytilus edulis, in each of seven size classes $(15,20,25,30,35,40$ and $45 \pm 1 \mathrm{~mm}$ shell length) by uninfected $(\mathrm{n}=28)$ and Sacculina infected $(\mathrm{n}=22)$ shore crabs (Carcinus maenas) during a 15-day laboratory experiment. Ten mussels were offered in each size category. 
direct observations during the experiment, the smallest mussels (15 mm) were generally opened by outright crushing, whereas mussels between 20 and $30 \mathrm{~mm}$ were typically opened by crushing at the anterior end close to the umbonal region. Larger blue mussels could not generally be crushed by the crabs and were most frequently opened at the posterior edge by chipping. Otherwise, these mussels were opened by boring or occasionally by squeezing the claw in between the two shell-halves of the mussel. The opening technique for a given mussel size appeared similar for the uninfected and infected crabs (see Elner, 1978 for description of techniques).

Including all size classes, the total number of blue mussels consumed during the experiment did not differ between the uninfected and infected crabs (paired $t$-test, $t_{21}=0.873, p=0.393$ ) nor was the number of mussels consumed in each of the seven size classes significantly different between the uninfected and infected crabs (all pair-wise comparisons; paired $t$-test, $t_{21} \leq 1.843, p \geq 0.080$, Fig. 4). Nevertheless, infected crabs tended to select 25-30 mm mussels less frequently than uninfected crabs (Fig. 4), and if the data for these two mussel sizes are combined, by which the variance is stabilized, infected crabs do indeed consume significantly less (26.0\%) 25$30 \mathrm{~mm}$ mussels than uninfected crabs (paired $t$-test, $t_{21}=2.488$, $p=0.021$ ). The relatively lower predation rate on $25-30 \mathrm{~mm}$ mussels seen in infected crabs appears off-set by a slightly higher consumption of both smaller and larger sized mussels (Fig. 4).

Although prey size selection differed slightly between the infected and uninfected crabs, the shell length at which $50 \%$ of the offered blue mussels were eaten ( $\mathrm{LS}_{50}$ value, corresponding to median prey size) was independent of infection status (paired $t$-test correcting for carapace width, $t_{21}=1.435, p=0.167$ ). The mean $\mathrm{LS}_{50}$ values were $25.5 \pm 1.0 \mathrm{~mm}$ for infected and $24.4 \pm 0.9 \mathrm{~mm}$ for uninfected individuals. This suggests that the relatively smaller claws of infected crabs had no marked negative bearing on median prey size or, if it has, it is offset by an opposite effect of infection per se. In terms of total dry weight of mussel tissue, the infected and uninfected crabs also consumed similar amounts during the experiment (1239.6 and $1321.2 \mathrm{mg}$ per capita, respectively; paired $t$-test, $t_{21}=0.488, p=$ 0.630 ).

The $\mathrm{LS}_{50}$ was for both infected and uninfected crabs a strong positive function of carapace width (linear regression, $\mathrm{df}=20-26: r^{2} \geq 0.440$, $p<0.0005)$ as well as propal height of largest claw $\left(r^{2} \geq 0.329\right.$, $p \leq 0.001$ ). Because of severe co-linearity (as evidenced by multiple regression analysis) it was not possible to separate statistically the relative influence of these two factors on $\mathrm{LS}_{50}$. As carapace width was corrected for in the paired $t$-tests above, a single full model ANCOVA was carried out including $\mathrm{LS}_{50}$ as dependent variable, infection status as fixed factor and maximum propal height as covariate. There was no claw-infection interaction $\left(F_{1,46}=0.304, p=0.584\right)$, and a subsequent reduced model demonstrated no effect of infection $\left(F_{1,47}=\right.$ $0.940, p=0.337)$ but significant effect of claw height $\left(F_{1,47}=32.97\right.$, $p<0.0005)$. Hence, infection status had no impact on $\mathrm{LS}_{50}$ for a given claw size, and it follows that neither infection per se, nor the resulting smaller claw size influences median prey size to any measurable extent. Combining the infected and uninfected crabs, the relationship between median mussel prey size and maximum claw height $(\mathrm{MCH})$ is $\mathrm{LS}_{50}(\mathrm{~mm})=1.288 \mathrm{MCH}(\mathrm{mm})+10.469 \quad\left(r_{48}^{2}=0.409, \quad p<0.0005\right.$; Fig. 5).

In accordance with the consumption rate experiment (Section 3.1), the dry weight and the carapace width of the crabs were positively correlated both among uninfected $\left(r_{26}^{2}=0.945, p<0.0005\right)$ and infected $\left(r^{2}{ }_{20}=0.955, p<0.0005\right)$ individuals (Fig. 3B). A full model ANCOVA on crab dry weight, including infection status as fixed factor and carapace width as covariate revealed a significant effect of carapace width $\left(F_{1,46}=866.45, p<0.0005\right)$ and no dry weight-infection status interaction $\left(F_{1,46}=0.312, p=0.579\right)$. A reduced model including the interaction term in the error variance demonstrated a highly significant effect of infection status on dry weight of the crabs $\left(F_{1,47}=13.00\right.$,

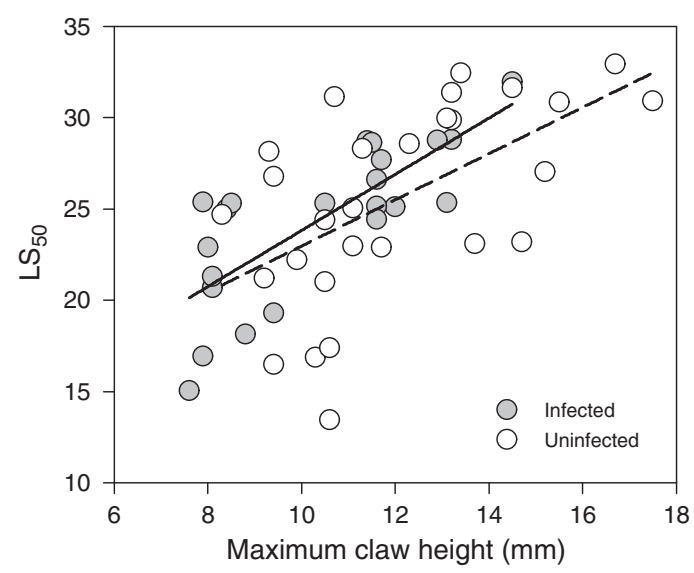

Fig. 5. The relationship between median mussel sizes consumed $\left(\mathrm{LS}_{50}\right)$ and maximum claw height (MCH) for Sacculina infected (closed circles, unbroken line) and uninfected (open circles, broken line) shore crabs (Carcinus maenas). See Section 2.3 and text to Fig. 4 for details. Linear regression including both infected and uninfected crabs: $\mathrm{LS}_{50}(\mathrm{~mm})=1.288 \mathrm{MCH}(\mathrm{mm})+10.469\left(r_{48}^{2}=0.409, p<0.0005\right)$

$p<0.0005$; Fig. 3B): infected crabs weighed on average $4.4 \%$ less than uninfected individuals. The propal height of the right and the left claw as well as RAW were significantly lower (12.8, 10.3 and $17.9 \%$, respectively) for Sacculina infected crabs compared to uninfected conspecifics (paired $t$-test, $t_{21} \geq 2.794, p \leq 0.011$ ). These morphological differences between the uninfected and infected crabs are indicative of host feminization caused by S. carcini.

\section{Discussion}

\subsection{Consumption rate}

The present result demonstrates that infection by $S$. carcini does not significantly affect male shore crabs per capita consumption of blue mussels ( $M$. edulis), neither in terms of numbers nor in terms of tissue dry weight, and regardless whether the crabs were offered ad libitum small, easy-to-handle mussels or a more challenging size-structured prey population. The conclusion is unlikely to be a type II error in light of the relatively large sample size (power) and the small differences in mean values obtained.

This is a surprising result because the vast majority of studies on contrasted consumption rates of the infected and uninfected individuals across a wide range of terrestrial and aquatic host-parasite systems show effects of parasitism: parasite-induced reduced consumption by hosts is 5 -fold more frequently reported than unchanged or increased consumption (see review by Moore, 2002). This also applies to aquatic, mainly marine, invertebrates. The consumption rate of coastal gastropods such as Ilyanassa obsoleta and Littorina littorea is markedly reduced when infected by various trematode species (Clausen et al., 2008; Curtis and Hurd, 1981; Larsen and Mouritsen, 2009; Wood et al., 2007), mud snails (Hydrobia ulvae) being an exception (Mouritsen and Jensen, 1994), and studied copepods, amphipods, isopods and decapods also show reduced consumption when infected by various helminth worms or parasitic isopods (Bass and Weis, 1999; Brown and Pascoe, 1989; Hernandez and Sukhdeo, 2008; Pascoe et al., 1995; Pasternak et al., 1995; see Crompton, 1970, for an exception). Aside from the present study, no studies have been conducted on any crab-rhizocephalan association.

Based on the dry weight-carapace width relationships, Sacculina infected crabs appeared to be in a relatively poorer condition than uninfected specimens, which cooperates well with an earlier finding (Mouritsen and Jensen, 2006) and, in turn, argues for a compensatory higher intake rate of infected crabs. However, the difference in size-corrected dry weight between the infected and uninfected 
crabs found here as well as by Mouritsen and Jensen (2006), may for the greatest part result from the morphological feminization induced by Sacculina. Admittedly, such feminization broadens the abdomen of the male host but on the other hand also reduces claw size significantly (Kristensen et al., 2012; present data). On top of this, also walking legs are reduced in length on infected specimens (Kristensen et al., 2012). Hence, the nutritional status, for instance in terms of energy per unit soft-tissue, might well be similar between the infected and uninfected crabs, which argues for also similar hunger levels and thus similar consumption rates. This contention is supported also by the observed similar prey size selection of the infected and uninfected crabs (see below) as hungry crabs tend to select larger bivalve prey than they otherwise would do (Hughes and Seed, 1995; Micheli, 1995). Therefore, it seems that the infection strategy of S. carcini is well-adapted to extract exactly the amount of resources the host allocates to reproductive organs and growth. Sacculina infection results in host castration/sterilization as well as ceased molting and therefore host growth (Høeg, 1995). Because host consumption is unaffected by infection, the energy requirements of the parasite must match these released energy pools, as also predicted by Høeg (1995).

\subsection{Prey size selection}

Neither infection per se nor the resulting reduced claw size appears to influence the median prey size $\left(\mathrm{LS}_{50}\right)$ of male shore crabs feeding on blue mussels. In crabs, prey selection is in part linked to chelal morphometry, because the crushing power of the chelipeds is positively related to their size (Elner, 1980; Kaiser et al., 1990; Lee, 1993; Reid et al., 1997; Sneddon et al., 2000; this study). Female shore crabs have relatively smaller claws than males. Accordingly, females often prey on smaller hard-bodied prey items than males, because such prey is easier/faster to crush (Elner, 1980; Lee and Seed, 1992; Spooner et al., 2007). Although Sacculina infected male shore crabs develop smaller claws than those possessed by uninfected males, this morphological feminization is incomplete (Kristensen et al., 2012) and apparently insufficient to influence overall median prey size significantly. Alternatively, because Sacculina infection in its external phase inhibits molting, a potential claw size determined reduction in median prey size of infected crabs may have been off-set by stronger claws that follow from longer inter-molt duration (see Kaiser et al, 1990; Reid et al., 1997). Nevertheless, infected crabs preyed less frequently on intermediate sized mussels than uninfected crabs, off-set by consumption of slightly more smaller and larger sized mussels. This can be reconciled with an unaffected median prey size and consumption rate following infection, and may all else being equal reflect the nonetheless somewhat smaller chelipeds of infected crabs. These crabs will sooner experience difficulties in opening mussels by outright crushing at increasing mussel sizes than uninfected crabs, and therefore to a larger extent turn their attention towards smaller easy-to-crush mussels or larger, more profitable mussels requiring other handling methods than application of raw claw force (i.e. chipping, boring or squeezing claws between shell-valves; see Section 3.2).

\subsection{Ecological consequences}

Under the assumption that obtained results can be extrapolated to the field, the above account suggests that $S$. carcini has no measurable indirect effect on its hosts prey population, here blue mussels (M. edulis), as a consequence of parasite-induced changes in the feeding behavior of male crabs. Nevertheless, infected crabs do seem to prey less frequently on intermediate sized mussel than uninfected crabs, and this might affect the size distribution of mussels in areas where parasitism is high. However, we judge such potential ecological impact to be overridden in situ by two other aspects of the
Sacculina-Carcinus association: (1) infection increases host mortality (Goddard et al., 2005; Torchin et al., 2001; present study), and (2) infection inhibits molt and hence growth of its host (Høeg, 1995). Where parasitism is high, this will mitigate the overall predation pressure on prey populations if $S$. carcini indeed is able to regulate its host population in situ (see Torchin et al., 2001). Furthermore, blue mussels will reach a size refugee from crab predation earlier than otherwise the case, because median prey size is a positive function of predator size (Fig. 5). Because crabs were collected in the field, it has to be emphasized that the observed higher mortality of infected crabs could in principle be a result of weak, moribund crabs becoming more frequently infected rather than a direct parasite-induced effect.

Although present analysis indicates a close to neutral effect of Sacculina infection on the feeding biology of its host, it should be stressed that experimental crabs were offered solely mussel prey. The diet of shore crabs is diverse, and in a few other host-parasite systems, infection has been reported to affect the relative importance of different exploited food sources (Médoc et al., 2011; Moore, 2002). Therefore, we cannot rule out that crabs, if given a choice, will prefer, for instance, more soft-bodied prey over mussels than uninfected crabs.

\section{Acknowledgments}

We wish to thank Sissel N. S. Geyti for providing photos of infected crabs and the staff of the Danish Shellfish Center, Nykøbing Mors, Denmark, for collecting the experimental animals. We are grateful to Trine T. Frankær, Sanne H. Larsen, and Inge Buss for their assistance in the laboratory. We are indebted to the Carlsberg Foundation for the financial support (grant number 2008-01-0491). [ST]

\section{References}

Baeta, A., Cabral, H.N., Marques, J.C., Pardal, M.A., 2006. Feeding ecology of the green crab, Carcinus maenas (L., 1758) in a temperate estuary, Portugal. Crustaceana 79, 1181-1193.

Bass, C.S., Weis, J.S., 1999. Behavioral changes in the grass shrimp, Palaemonetes pugio (Holthuis), induced by the parasitic isopod, Probopyrus pandalicola (Packard). J Exp. Mar. Biol. Ecol. 241, 223-233.

Brown, A.F., Pascoe, D., 1989. Parasitism and host sensitivity to cadmium: an acanthocephalan infection of the freshwater amphipod Gammarus pulex. J. Appl. Ecol. 26, 473-487.

Bruzzone, O.A., Corley, J.C., 2011. Which is the best experimental design in animal choice tests? Anim. Behav. 82, 161-169.

Burch, A., Seed, R., 2000. Foraging behaviour of Carcinus maenas on Mytilus edulis: the importance of prey presentation. J. Mar. Biol. Assoc. U. K. 80, 799-810.

Clausen, K.T., Larsen, M.H., Iversen, N.K., Mouritsen, K.N., 2008. The influence of trematodes on the macroalgae consumption by the common periwinkle Littorina littorea. J. Mar. Biol. Assoc. U. K. 88, 1481-1485.

Crompton, D.W.T., 1970. An Ecological Approach to Acanthocephalan Physiology. Cambridge University Press, Cambridge.

Curtis, L.A., Hurd, L.E., 1981. Nutrient procurement strategy of depost-feeding estuarine neogastropod, Ilyanassa obsoleta. Estuar. Coast. Shelf Sci. 13, 277-285.

Darling, J.A., Bagley, M.J., Roman, J., Tepolt, C.K., Gellers, J.B., 2008. Genetic patterns across multiple introductions of the globally invasive crab genus Carcinus. Mol. Ecol. 17, 4992-5007.

Elner, R.W., 1978. The mechanisms of predation by the shore crab, Carcinus maenas (L.), on the edible mussel, Mytilus edulis L.Oecologia 36, 333-344.

Elner, R.W., 1980. The influence of temperature, sex and chela size in the foraging strategy of the shore crab, Carcinus maenas (L.). Mar. Behav. Physiol. 7, 15-24.

Elner, R.W., Hughes, R.N., 1978. Energy maximization in the diet of the shore crab, Carcinus maenas. J. Anim. Ecol. 47, 103-116.

Goddard, J.H.R., Torchin, M.E., Kuris, A.M., Lafferty, K.D., 2005. Host specificity of Sacculina carcini, a potential biological control agent of introduced European green crabs Carcinus maenas in California. Biol. Invasions 7, 895-912.

Grosholz, E.D., Ruiz, G.M., 1995. Spread and potential impact of the recently introduced European green crab, Carcinus maenas, in central California. Mar. Biol. 122, 239-247.

Grosholz, E.D., Ruiz, G.M., Dean, C.A., Shirley, K.A., Maron, J.L., Connors, P.G., 2000. The impacts of a nonindigenous marine predator in a California Bay. Ecology 81, 1206-1224.

Hernandez, A.D., Sukhdeo, M.V.K., 2008. Parasite effects on isopod feeding rates can alter the host's functional role in a natural stream ecosystem. Int. J. Parasitol. 38 683-690.

Høeg, J.T., 1995. The biology and life cycle of the Rhizocephala (Cirripedia). J. Mar. Biol. Assoc. U. K. 75, 517-550. 
Høeg, J.T., Lützen, J., 1995. Life cycle and reproduction in the Cirripedia Rhizocephala. Oceanogr. Mar. Biol. Annu. Rev. 33, 427-485.

Hughes, R.N., Seed, R., 1995. Behavioural mechanisms of prey selection in crabs. J. Exp. Mar. Biol. Ecol. 193, 225-238.

Kaiser, M.J., Hughes, R.N., Reid, D.G., 1990. Chelal morphometry, prey-size selection and aggressive competition in green and red forms of Carcinus maenas (L.) J. Exp. Mar. Biol. Ecol. 140, 121-134.

Kristensen, T., Nielsen, A.I., Jørgensen, A.I., Mouritsen, K.N., Glenner, H., Christensen, J.T., Lützen, J., Høeg, J.T., 2012. The selective advantage of host feminization: a case study of the green crab Carcinus maenas and the parasitic barnacle Sacculina carcini. Mar. Biol. 159, 2015-2023.

Lafferty, K.D., Kuris, A.M., 2009. Parasitic castration: the evolution and ecology of body snatchers. Trends Parasitol. 25, 564-572.

Larsen, M.H., Mouritsen, K.N., 2009. Increasing temperature counteracts the impact of parasitism on periwinkle consumption. Mar. Ecol. Prog. Ser. 383, 141-149.

Lee, S.Y., 1993. Chela height is an acceptable indicator of chela strength in Carcinus maenas (L.). Crustaceana 65, 115-116.

Lee, S.Y., Seed, R., 1992. Ecological implications of cheliped size in crabs: some data from Carcinus maenas and Liocarcinus holsatus. Mar. Ecol. Prog. Ser. 84, 151-160.

Lützen, J., 1984. Growth, reproduction, and life span in Sacculina carcini Thompson (Cirripedia: Rhizocephala) in the Isefjord, Denmark. Sarsia 69, 91-105.

Mascaró, M., Seed, R., 2001. Choice of prey size and species in Carcinus maenas (L) feeding on four bivalves of contrasting shell morphology. Hydrobiologia 449, 159-170.

Mathieson, S., Berry, A.J., Kennedy, S., 1998. The parasitic rhizocephalan barnacle Sacculina carcini in crabs of the Forth Estuary, Scotland. J. Mar. Biol. Assoc. U. K. 78, 665-667.

Médoc, V., Piscart, C., Maazouzi, C., Simon, L., Beisel, J.-N., 2011. Parasite-induced changes in the diet of a freshwater amphipod: field and laboratory evidence. Parasitology 138, 537-546.

Micheli, F., 1995. Behavioural plasticity in prey-size selection of the blue crab Callinectes sapidus feeding on bivalve prey. J. Anim. Ecol. 64, 63-74.

Moore, J., 2002. Parasites and the Behavior of Animals. Oxford University Press, Oxford.

Mouritsen, K.N., Haun, S.C.B., 2008. Community regulation by herbivore parasitism and density: trait-mediated indirect interactions in the intertidal. J. Exp. Mar. Biol. Ecol. 367, 236-246.

Mouritsen, K.N., Jensen, K.T., 1994. The enigma of gigantism: effect of larval trematodes on growth, fecundity, egestion and locomotion in Hydrobia ulvae (Pennant) (Gastropoda: Prosobranchia). J. Exp. Mar. Biol. Ecol. 181, 53-66.

Mouritsen, K.N., Jensen, T., 2006. The effect of Sacculina carcini infections on the fouling, burying behaviour and condition of the shore crab, Carcinus maenas. Mar. Biol. Res. 2, 270-275.

Mouritsen, K.N., Poulin, R., 2002. Parasitism, community structure and biodiversity in intertidal ecosystems. Parasitology 124, S101-S117.
Mouritsen, K.N., Poulin, R., 2010. Parasitism as a determinant of community structure on intertidal flats. Mar. Biol. 157, 201-213.

Pascoe, D., Kedward, T.J., Blackwell, S.J., Taylor, E.J., 1995. Gammarus pulex (L.): feeding bioassay - effects of parasitism. Bull. Environ. Contam. Toxicol. 55, 629-632.

Pasternak, A.F., Huntingford, F.A., Crompton, D.W.T., 1995. Changes in metabolism and behaviour of the freshwater copepod Cyclops strenuous abyssorum infected with Diphyllobothrium spp. Parasitology 110, 395-399.

Raffaelli, D. Conacher, A McLachlan, H. Emes, C, 1989. The role of epibenthic crustacean predators in an estuarine food web. Estuar. Coast. Shelf Sci. 28, 149-160.

Rasmussen, E., 1973. Systematics and the ecology of the Isefjord marine fauna (Denmark). Ophelia 11, 142-165.

Reid, D.G., Abelló, P., Kaiser, M.J., Warman, C.G., 1997. Carapace colour, inter-moult duration and the behavioural and physiological ecology of the shore crab Carcinus maenas. Estuar. Coast. Shelf Sci. 44, 203-211.

Reise, K., 1985. Tidal Flat Ecology. An Experimental Approach to Species Interactions. Springer-Verlag, Berlin.

Roa, R., 1992. Design and analysis of multiple-choice feeding-preference experiments. Oecologia 89, 509-515.

Sneddon, L.U., Huntingford, F.A., Taylor, A.C., Orr, J.F., 2000. Weapon strength and competitive success in fights of shore crabs (Carcinus maenas). J. Zool. (Lond.) 250, 397-403.

Sousa, W.P., 1991. Can models of soft-sediment community structure be complete without parasites? Am. Zool. 31, 821-830.

Spooner, E.H., Coleman, R.A., Attrill, M.J., 2007. Sex difference in body morphology and multitrophic interactions involving the foraging behaviour of the crab Carcinus maenas. Mar. Ecol. 28, 394-403.

Thresher, R.E., Werner, M., Høeg, J.T., Svane, I., Glenner, H., Murphy, N., Wittwer, C., 2000. Developing the options for managing marine pests: specificity trails on the parasitic castrator, Sacculina carcini, against the European crab, Carcinus maenas, and related species. J. Exp. Mar. Biol. Ecol. 254, 37-51.

Torchin, M.E., Lafferty, K.D., Kuris, A.M., 2001. Release from parasites as natural enemies: increased performance of a globally introduced marine crab. Biol. Invasions $3,333-345$

Werner, M., 2001. Prevalence of the parasite Sacculina carcini Thompson 1836 (Crustacea, Rhizocephala) on its host crab Carcinus maenas (L.) on the west coast of Sweden. Ophelia 55, 101-110.

Wood, C.L., Byers, J.E., Cottingham, K.L., Altman, I., Donahue, M.J., Blakeslee, A.M.H., 2007. Parasites alter community structure. Proc. Natl. Acad. Sci. 104, 9335-9339.

Zetlmeisl, C., Hermann, J., Petney, T., Glenner, H., Griffiths, C., Taraschewski, H., 2011. Parasites of the shore crab Carcinus maenas (L.): implications for reproductive potential and invasion success. Parasitology 138, 394-401. 